\title{
Correction to: Effects of reward magnitude and training frequency on the learning rates and memory retention of the Port Jackson shark Heterodontus portusjacksoni
}

\author{
Dennis D. U. Heinrich ${ }^{1}$ (D) . Catarina Vila Pouca ${ }^{2,3} \cdot$ Culum Brown $^{4} \cdot$ Charlie Huveneers $^{1}$
}

Published online: 30 June 2020

(c) Springer-Verlag GmbH Germany, part of Springer Nature 2020

\section{Correction to: Animal Cognition}

https://doi.org/10.1007/s10071-020-01402-2

In the original publication of the article, the Fig. 4 was erroneously published. The corrected Fig. 4 has been attached.

Publisher's Note Springer Nature remains neutral with regard to jurisdictional claims in published maps and institutional affiliations.

The original article can be found online at https://doi.org/10.1007/ s10071-020-01402-2.

Dennis D. U. Heinrich

hein0116@flinders.edu.au

1 College of Science and Engineering, Flinders University, Sturt Road, Adelaide, SA, Australia

2 Zoological Institute, Stockholm University, 10691 Stockholm, Sweden

3 Behavioural Ecology Group, Wageningen University \& Research, Wageningen, The Netherlands

4 Department of Biological Sciences, Macquarie University, Innovation Drive, Sydney, NSW, Australia 

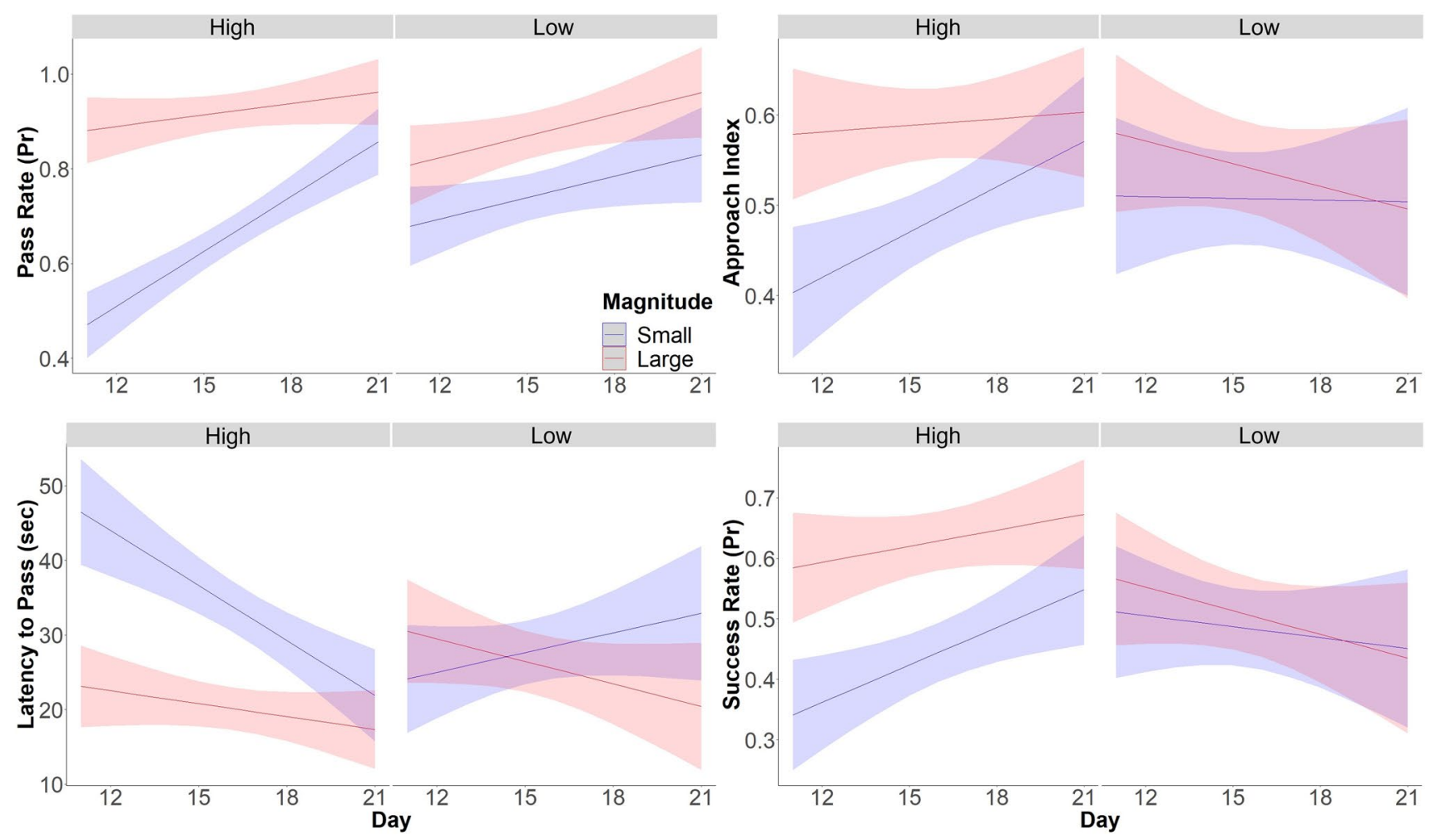

Fig. 4 Interaction effect between the reinforcement frequency (left: high, right: low), the reward magnitude (blue: small, red: large), and the experimental day on $\mathbf{a}$ pass rate, $\mathbf{b}$ approach index, $\mathbf{c}$ latency to pass the correct door, and $\mathbf{d}$ success rate with $95 \%$ confidence bands.

Reinforcement frequency and reward magnitude had a significant interaction effect on the latency to pass with large-reward sharks learning significantly faster when subjected to a low reinforcement frequency (color figure online) 